Aus der Chirurgischen Universitätsklinik in Würzburg. (Direktor: Geh.-Rat König.)

\title{
Zur Wundbakterienflora.
}

Von Dr. W. J. Klug, Assistent an der Klinik.

Unsere Kenntnis über die Wundbakterienflora erstreckt sich bis jetzt auf das Vorkommen von Staphylococcus pyogenes aureus und albus, Streptokokken, Diplostreptokokken, Bacillus pyocyaneus, Grampositiven Diplokokken, Gram-positiven und Gram-negativen Bazillen, Pneumokokken und Gram-negativen Diplokokken, also die hauptsächlich in lang eiternden Wunden vorkommenden Eitererreger Staphylound Streptokokken und Pyozyaneus. In den letzten Kriegsjahren und den darauf folgenden ist es gelungen, das Mikrobenbild zu bereichern durch die Feststellung von Diphtheriebazillen in allen möglichen Arten von Wunden, in welche sie durch Sekundärinfektion gelangt sein sollen. Membranöse und schmierige Beläge veranlaßten die einzelnen Autoren zur bakteriologischen Untersuchung der jeweiligen Wunden und führten zu dem zunächst staunenerregenden Befund der Wunddiphtherie. Systematische Untersuchungen ganzer Reihen von Wunden verdächtigen und sozusagen normalen Aussehens erbrachten oft den Löffler-Bazillus und damit die Erklärung für den örtlichen hartnäckigen Wund- und auch Allgemeinbefund der befallenen Patienten.

In Folgendem soll nun nicht über Wunddiphtherie abgehandelt, sondern über einen $F$ all berichtet werden, der in einer $O p e$ rationswunde Keime enthielt, die genau wie der Löffler-Bazillus im Mundrachenraum pathogen auftreten und ein Krankheitsbild erzeugenkönnen, das sich von der Diphtherie nur bakteriologisch unterscheiden lassen kann.

Ein 30jähriger Mann, der im Felde Ruhr und Gelenkrheumatismus durchgemacht, vor 10 Jahren eine Angina und sonst nie ähnliche Halsbeschwerden gehabt hat, erkrankte an Appendizitis, wird 72 Stunden nach den ersten Anfällen operiert. Es wird ein fast total gangränöser Wurmfortsatz entfernt. Im Verlaufe der Behandlung stellt sich eine typische Fasziennekrose, daran anschlieBend' eine Thrombose der Vena saphena links und eine weniger ausgeprägte der Vena saphena rechts ein, die zur Lungenembolie mit darauffolgender Pneumonie im linken Unterlappen und einige Zeit später auch im rechten Unterlappen führt. Dauerndes Fieber, Schüttelfröste. Häufiges Erbrechen. Das Zusammentreffen so vieler Krankheiten der verschiedensten Organe läßt den Verdacht auf Sepsis aufkommen. In dem Bestreben, dem schwer erkrankten Manne durch eine spezifische Behandlung Genesung zu verschaffen, sollte die Autovakzinationstherapie eingeschlagen werden. Es wurden daher mehrere Kubikzentimeter Blut aus der Kubitalvene und Eiter aus der Operationswunde zwecks Herstellung der Autovakzine entnom. men. Dr. Bärthlein vom hiesigen Hygienischen Institut übernahm die Untersuchung und fand nun das Blut völlig keimfrei. Im Wundsekret außer einigen Kokken ausgedehnte Nester von Bacillus fusiformis und Spirochäten. 
Wir haben also in einer seit Wochen eiternden Granulationswunde nach Appendektomie Fusiformes und Spirochäten, 2 symbiotisch lebende Keime, wie sie die bekannte Angina Plaut-Vincent aufweist. Hört man diese Namen, so stellt man sich ohne weiteres schwerc Krankheitsbilder mit hohem Fieber, schweren Allgemeinzuständen und örtlichen ulzeromembranösen nekrotischen Partien der Tonsillen vor.

Besehen wir uns nun die Wunde von unserem Patienten, so zeigt sie keine Spur von Nekrose, von Ulkus, von Membranen. Es ist deutliche frischrote Granulationsbildung vorhanden, wie man sie meistens bei Appendektomiewunden, bei denen keine Hautnaht gelegt war, sieht. Die Granulationen bluten bei der geringsten Berührung, die Wundfläche hat immer die gleiche Ausdehnung, das heißt wenig Neigung zum Epithelialisieren. Beim Druck auf die Wundumgebung kommen an zwei Stellen aus der "Tiefe noch einige Kubikzentimeter grüngelben, mäßig dicken Eiters, der aber keinen stinkenden Geruch hat. Auffallend ist die Schmerzempfindlichkeit der Granulationen an einigen Stellen. Unser Wundbild zeigt also, alles zusammengenommen, wenig für Plaut-Vincent Charakteristisches. Anders steht es mit dem Allgemeinbefinden. Wie schon früher erwähnt, bestanden ständig hohes Fieber, dazwischen kurze Remissionen, Kopfweh, Brechreiz und Erbrechen. Ob diese Erscheinungen dem Vorhandensein der Plaut-Vincentschen Keime zur Last gelegt werden müssen oder durch die Thrombose, Embolie und Pneumonie bedingt sind, will ich hier nicht ohne weiteres entscheiden. Ich komme später noch einmal darauf zurück.

Halten wir nun in der Literatur Umschau, so wird uns berichtet, daß bei Tierversuchen Abszesse sowohl von Fusiformes als auch von Spirochäten allein, sowie von beiden zusammen erzeugt wurden: So gelang es Sillberschmidt, subkutane und intramuskuläre Abszesse bei entsprechenden Injektionen von Fusiformes und Spirochäten vergesellschaftet mit Kokken und olne solche hervorzurufen, während Veszprémi durch Uebertragung von Eiter einer Oberkieferperiostitis jauchig-eitrige Peritonitis sah, in deren Exsudat außer Kokken eine große Anzahl „fusiformer Bazillen und Spirillen" vorhanden war. Er erreichte ferner bei subkutanen, intramuskulären Tierversuchen von Kulturen gangränöse. Abszesse, die starke Abmagerung und allmäbliches Zugrundegehen der Tiere herbeiführten. Anderen Autoren ist es gelungen, Fusiformes und Spirochäten zusammen oder getrennt nicht nur bei den verschiedensten Wundaffektionen, sondern auch bei gangränösen Abszessen verschiedenster Organe nachzuweisen. Ich erinnere an den $\mathrm{Ba}$ cillus hastilis von Seitz, der bei fötiden Affektionen des Respirations- und Digestionstraktus gefunden wurde und mit Fusiformis identisch erklärt wird. Bernheim und Pospischill erwähnen Fusiformis und Spirochäten bei Noma. Ve illo t1 und Zuber haben bei zahlreichen putriden bzw. gangränösen Prozessen, wie Otitis media, Meningitis purulenta, Zahnabszessen, Halsphlegmonen, Lungengangrän, Empyem, Leberabszeß, Appendizitis usw., ein, ihrer Meinung nach, dem Fusiformis identisches Stäbchen kultiviert. S iI bèrschmidt und Veszprémi fanden Fusiformes und Spirochäten bei Hirnabszessen. Ei chm e y e $r$ hat sie bei außerordentlich zahlreichen eitrigen und nekrotischen bzw. gangränösen Prozessen beobachtet.

Wie weit es sich hier tatsächlich um Fusiformis- und Spirochätenaffektionen oder um andere handelt, will ich unentschieden lassen. Die Literaturangaben sollen nur als Wegweiser für die Möglichkeit des Auftretens der beiden Mikroben in unserem. Falle dienen. Obige Mitteilungen liegen teilweise so weit zurück, daß sie nur denen bekannt sein können, die sich eingehend mit der Angina PlautVincent oder mit den sie hervorrufenden Mikroben beschäftigen. Der Kliniker als solcher wird gewohnt sein, Fusiformes und Spirochäten auf der Schleimhaut der Mundhöhle, am Zahnfleischrand und in kariösen Zähnen, von wo ausgehend die Keime virulent werden und zil den bekannten ulzeromembranösen Prozessen ' führen, anzunehmen. Er wird diesen Befund vermuten bei Rachitikern und Skrofulösen, die, nach Bohn, zur Stomatitis tulcerosa neigell, bzw. vielleicht bei übermäßigen Rauchern, die nach den Franzosen $\mathrm{Ni}$ klot und Marotte und auch nach deutschen Beobachtern, wie $S$ alomon und GroB, oft mit ulzeröser Stomatitis behaftet sein sollen, wird sie bei Diphtherie, luetischen, tuberkulösen und karzinomatösen Geschwüren, wo sie Vincent, Letulle, Salomon, Niklot, Löblowitz, GroB usw. beobachteten, erwarten dürfen.

Wie aber soll man sich das Vorhandensein voil Fusiformes und Spirochäten auf einer Wunde, die unter relativ aseptischen Kaufelen gesetzt worden ist, erklären? Nach Vincent, Niklot, $M$ arotte u. a. bevorzugen die fusiformen Bazillen die Symbiose mit den Eiterbakterien; Letulle, de Stoecklin, Preisich und Rodella nehmen an, daß die pyogenen Bakterien erst einen günstigen Nährboden vorbereiten, in den dann sekundär die Fusiformes eindringen und durch Ueberwuchern der ersteren dem Krankheitsbild ihr Charakteristikum aufprägen. $\mathrm{Zu}$ ihnen gesellen sich dann die Spirochäten, die lediglich als Saprophyten auftreten sollen (A bel, G roB usw.).

Wenden wir nun all diese Feststellungen auf unseren Fall an, so kainn es sich nur um folgende Möglichkeiten für das Auftreten der Plaut-Vincent-Mikroben in der Operationswunde handeln. Entweder sind sie in die durch den gangränösen Wurmfortsatz bedingte Bauchdeckeneiterung sekundär durch Uebertragung von zweiten und dritten Personen gelangt, oder die ganze Appendizitiserkrankung ist der Effekt einer Fusiformis- und Spirochäteninfektion gewesen und hat deren Auftreten in Wundsekret bedingt.
Für die Uebertragung durch andere Personen bestehen keinerlei Anhaltspurkte. Der Patient wurde stets von einem Arzt unter aseptischen Maßnalımen verbunden. Dieser sowie das Pflegepersonal und die benachbatten Patienten hatten keinerlei Mund- und Rachenaffektionen, nicht einmal eine einfache Angina war während der ganzen Zeit auf der Station. Mit größter Wahrscheinlichkeit kaun also die Infektion von dieser Seite aus ausgeschlossen werden. Gleichzeitig mit dieser Feststellung ist wohl auch das alte Gespenst des Hospitalbrandes gebannt, das sich einem unwillkürlich aufdrängt, weil seine Erreger ja von manchen Autoren als identisch mit den Fusiformes erachtet werden, die durch Uebertragung im Spital selbst bei Verbandwechsel usw. iene lange Zeit gefürchtete Infektion hervorriefen.

Somit bleibt als Erklärung nur der zweite Modus übrig. Hierfür haben wir eine Reihe von Anhaltspunkten. In der Literatur sind, wie schon weiter oben erwähnt, bereits Appendizitiden beschrieben, bei denen Fusiformes und Spirochäten gefunden wurden. W'ir wissen ferner, daß Fusiformes und Spirochäten, besonders letztere, in den verschiedensten Arten in der Mundhöhle und auch im Darm ihret Aufenthalt haben, wohin sie leicht genug mit der Nahrung gelangen und unter Umständen pathogen werden können. Ein Vergleich mit den Diphtheriebazillen, mit denen sie so oft gemeinsame Lokalisation haben, drängt sich mir als Ausbreitungsmodus auf, ich meine die Diphtheriebazillenträger, besonders die Hautdiphtheriebazillenträger von $L$ andé und $L$ ä we n.

Bei unserem Falle ist es aber gar nicht notwendig, so weit zu gehen. In seiner Mundhöhle sieht man plombierte und kariöse Zähne, Prädilektionsstellen genug, um mit größter Wahrscheinlichkeit auf sie als Ausgangspunkt für das Auftreten von Fusiformes und Spirochäten zt4 kommen. Diesbezügliche Untersuchungen waren zwar negativ, doch kann dies durch vorausgegangene Mundspülung, wegen einer nicht spezifischen Angina und Laryngitis bedingt gewesen sein. Man kann annehmen, daß auf rein enterogenem Wege bei unserem Falle es zu einer Erkrankung der Appendix durch Fusiformes und Spirochäten gekommen ist, wofür vielleicht die totale Gangrän des Wurmfortsatzes mit Belägen auf der Serosa und ohne jegliche Exsudatsbildung, wie man es häufig bei der Appendizitis durch die Begleitbarkeit der Fusiformes und Spirochäten, Streptokokken, sieht, spricht. Leider konnte keine diesbezügliche Untersuchung mehr vorgenommen werden, da das Präparat bereits vernichtet war. Bei der Entfernung des so erkrankten Wurmfortsatzes ist es, wie es sich ja oft nicht vermeiden läßt, zur Infektion der Bauchdecken gekommen, es hat sich eine Fasziennekrose, also der günstigste Nährboden für unsere beiden Keime entwickelt Damit ist nun auch das wenig charakteristische Aussehen der Granulationswunde erklärt. Der ganze Prozeß spielt sich in der Wundtiefe $a b$, die Wundfläche selbst läBt durch ihr harmloses Aussehen niemand diesen Bakterienbefund von Fusiformes und Spirochäten ahnen. Systematische Untersuchungen schwer heilender Appendektomiewunden nach dieser Hinsicht können vielleicht zur endgültigen Klärung führen. Ich muß mich heute mit der Feststellung des Fusiformis. und der Spirochäte in einer Operationswunde nach Appendektomie begnügen.

Zum Schlusse sei mir vielleicht noch ein kurzes Streiflicht auf den Zusammenhang dieses Bakterienbefundes mit dem jetzigen Krankheitszustand erlaubt. Thrombose, Embolien und Lungeninfarkte beherrschen jetzt das Krankheitsbild. Dazu kommen immer wieder Schüttelfröste, Magen- und Darmbeschwerden (Brechen und Brechreiz); hohe Fieberzacken wechseln mit tagelangen Remissionen. Auffallend und wohl damit zusammenhängend ist, daß die Temperatursteigerungen fast regelmäßig wieder mit einem neuen Lungeninfark und seinen Erscheinungen zusammenfällt. Sonst möchte ich fast annehmen, daß wir es hier von vornherein mit einer Spirochätenerkrankung zu tun haben, auf welche die Thrombose als hämotoxisches, die Magen- und Darmbeschwerden (Brechen und Brechreiz) als neurotoxisches Moment, die Schüttelfröste, Fieberzackẻn und Remissionen als Zeichen von Neuüberschwemmung des Körpers paßten.

W. Eich me ye r, Erg. d. allgem. Path. ${ }^{\circ} 1904 / 1905$. - Lub a r s ch-Ostert a g, Nach innen sind die meisten Autoren zitiert, soweit sie mir nicht persönlich bekannt waren. 